\title{
Report on The 70th IIW Annual Assembly and International Conference, Shanghai, China held on June 25-30, 2017
}

The 70th Annual Assembly was organized by the Chinese welding Society CWS at The Shanghai International Convention Centre, Shanghai from 25th - 30th June 2017.

The Event was attended by 1158 delegates and out of which close 380 young professionals attended the assembly and also participated actively. A small captive display stalls were in the 3rd floor of the sponsors of the event.

IIW India was represented by a team of 11 members out of which 3 from IIW officials, 2 from the industry, 6 from the research personnel from Academics from Pandit Deendayal Institute, IIT Roorke and IIT Chennai.

The General assembly on 25th was attended by R. Srinivasan President, Mr Parimal Biswas, Hony Secry. General and Dr M. Shome from Tata Steel.

The Inaugural ceremony was very crisp and quiet elegant. The award function was done with Precise execution. Glad to see Mr Parimal Biswas from IIW India was bestowed the Honours of the WG RA award winner. He was presented with a Crystal Trophy and a certificate duly framed along with cash Price of 1000 Euros. Mr Chris small Bone Has prepared the IIW history from 1992 to 2017 was released. He has given a copy of his book to IIW India as a compliment and also a Soft copy.

There were 6 Technical presentations by the team in Commission, III, XII, XV. And 6 presentations in the conference. Out of the 6 commission presentations 2 were in the YPIC. The team had lot of Interactions with the various groups and with Individual.

In the WG RA meeting 2 presentations were made by IIW India team of R. Srinivasan and Parimal Biswas on IC 2017 and on IC 2020. One Presentation was made in AAA meeting by $R$. Srinivasan on

IIW-India Role in the development of Make In India Project and was appreciated well. We had also made a presentation on the success story and the gains of the IIW Golden Jubilee celebrations

IIW India has awarded the IC 2020. Further the request has been made to SG RES to allot the Research colloquium in 2019 to India. We have also submitted our proposal to host the Annual Assembly in 2022. These decisions will be taken by the board and will communicate to us .

The Arc Cup Competition for welders was parallel organized by CWS at The venue of TAYER Industry about $50 \mathrm{Km}$ from the convention venue. Mr. Srinivasan and Mr. Biswas visited the place and met all the Indian participants of welders and the team leaders to encourage the contestants. We also attended the closing ceremony along with the Officials of IIW. The welders from India excelled in their competition and has bagged the 2nd and 3rd position in SMAW, GMAW and overall 3rd position on the team events. Thanks to the excellent efforts of Mr G. A. Soman, Chairman Best Welder Competition, with DBMA- Mumbai for training, and the consumable support by $\mathrm{M} / \mathrm{s}$. ADOR India Ltd. helped the participants from India could excel. Since this was the first time our welders from The Banner of IIW attended and it is great achievement.

The 71st Annual Assembly will be held at Bali, Indonesia in July 2018. The organisers have requested us to be member of the advisory group and we have agreed to assist to the best possible ways.

We had a meeting AWS team for co-operation for the Technical Lecture series and also for the Participation in IC 2017. Due to financial constraints and also they have not budgeted the expenses in this year has informed that they will not be able to support IIW India.

Had meeting with SG-RES and with TWI for the support for the 7th Research colloquium which will be hosted by TWI in September 2017. Had a meeting with Canadian Welding Society for closer co-operation between IIW and CWI

Had a meeting with Dr Cecile Mayer and with Douglas Lucianni, the President and invited then to join in IC 2017. Dr. Cecile Mayer agreed and also confirmed her participation. Mr. Douglas Luciani will confirm shortly.

About 100 IC 2017 Brochures were distributed in The WG RA, SG -RES and in the AAA meetings.

\section{About the Assembly and Conference:}

The 70th Annual Assembly of International Institute of Welding was held at Shanghai International Concention Center (SHICC), No. 2727 Binjiang Avenue, Shanghai, P. R. China during 25-28 June, 2017 and was divided in different technical commissions as under:

- C-I/Additive manufacturing, surfacing and thermal cutting

- C-II / Arc welding and filler metals

- C-III / Resistance welding, solid state welding and allied joining processes

- C-IV/Power beam processes 
- C-V / Non-destructive testing and quality assurance of welded products

- C-VI/Terminology

- C-VII / Research developments and applications in microand nano-joining technologies

- C-VIII / Health, safety and environment

- C-IX/ Behavior of metals subjected to welding

- C-X / Structural performances of welded joints - fracture avoidance

- C-XI/Pressure vessels, boilers and pipelines

- C-XII / Arc welding processes and production systems

- C-XIII / Fatigue of welded components and structures

- C-XIV/ Education and training

The International conference during 29-30 June 2017 had 6 parallel sessions according to the following topics as below:

- Advanced/green welding and joining processes;

- Simulation in welding;

- Welding of heavy plates, nonferrous metals and high strength materials;

- Additive manufacturing;

- Nano/micro welding and joining

- Others

\section{About papers presented at various commissions}

Narrow Gap Welding using Cored Wires : Vishvesh J. Badheka (India), Doc. XII-2326-17

Effect of change of directions during multiple pass friction stir processed AA6061/B4C composites (I-1310-17), Vishvesh Badheka, Vivek V. Patel, Samarth Zala, Utsav Patel, Sagar Patel, Swarg Patel

Investigation on the Activated TIG welding of Cr-Mo-V steels : Jay J. Vora, Vivek Patel, Sagar Suthar, Ashutosh Naik, Darshan

List of Indian Delegates :

\begin{tabular}{ll}
\hline Name & Organisation \\
\hline Dr. Murugaiyan Amrithalingam & Department of Metallurgical and Materials Engineering, IIT Madras \\
Mr. Ramkishor Anant & Indian Institute of Technology, Roorkee \\
Prof. \& Dr. Vishvesh Badheka & The Indian Institute of Welding \\
Mr. Parimal Biswas & The Indian Institute of Welding \\
Mr. Aloke Kumar Bose & The Indian Institute of Welding \\
Dr. Durga Janaki Ram Gabbita & Indian Institute of Technology, Madras \\
Dr. Vivek Patel & Pandit Deendayal Petroleum University \\
Mr. Suman Patra & Tata Steel \\
Dr. Mahadev Shome & Tata Steel, Jamshedpur \\
Mr. Ramachandran Srinivasan & The Indian Institute of Welding \\
Dr. Jaykumar Vora & Pandit Deendayal Petroleum University \\
\hline
\end{tabular}

Kundal, Ritesh Patel, Subhash Das (India) Doc. XII-2316-17

Hybrid friction stir processing with active cooling approach to achieve low temperature superplasticity in AA7075 alloy, by V.V. Patel, V. Badheka (India), III-1824-17

Magnetic Pulse Welding of dissimilar materials (i.e. Cu to Steel and Al to Steel), Mahadev Shome (India) III-1829-17

Joint strength and distortion during advanced gas metal arc joining of dissimilar alloys by Sven- $F$ Goecke, P. Makwana, M. Shome and A. De, was presented by Prof Goecke in C-XVII.

Hot Cracking Behavior of a Cast Nickel-Base Superalloy XH43 : P. Venkatesh, G.M. Karthik, S. Sudharsanan, G. D. Janaki Ram, M. Arithalingam \& Govind.

Stress Induced Precipitations and Transformations in the Heat Affected Zones of Micro-Alloyed Steels Welds : L. Dineshkumar \& Murugaiyan Amrithalingam.

Investigation on the Activated TIG welding of Cr-Mo-V steels : Jay J. Vora, Vivek PatelL, Sagar Suthar, Ashutosh Naik, Darshan Kundal, Ritesh PatelL, Subhash Das. Pandit Deendayal Petroleum University.

Advance technique to produce narrowest gap GMA weld joint of thick sections : Ramkishor Anant, P. K. Ghosh. IIT Roorkee.

Advances in activated flux processes : Vishvesh J Badheka

\section{Visit to the University}

Visited the Shanghi Jiao Tong University, Material science and engineering dept, followed by visit to laser processing centre.

\section{Exhibition}

Dr Badheka and Dr Shome visited the 22nd Beijing Essen Welding \& Cutting Fair at Shaghai.

\section{Paper presented at conference}

